\section{Triple plagiotropic branch in coffee: a new promising mutant?}

\author{
Ney Sussumu Sakiyama ${ }^{1 *}$, Edgard Augusto de Toledo Picoli ${ }^{2}$, \\ Antonio Carlos Baião de Oliveira ${ }^{3}$, Eveline Teixeira Caixeta ${ }^{4}$, \\ Laércio Zambolim ${ }^{5}$, Hermínia Emília Prieto Martinez ${ }^{1}$ and \\ Antonio Alves Pereira ${ }^{6}$
}

\begin{abstract}
Coffee tree is a shrub with dimorphic branches. The orthotropic stem grows vertically with two near-horizontal plagiotropic branches, per node, in opposite phyllotaxy. The consecutive nodes of the orthotropic stem are organized in parastichies. We report here mutant plants of Coffea arabica with triple plagiotropic branch, resulted from the whorled phyllotaxy of the orthotropic stem. In mutant plants three plagiotropic branches in the same node are separated by angles of approximately $120^{\circ}$, while in normal plants two plagiotropic branches in the same node are separated by angles of approximately $180^{\circ}$. In mutant plants the angles of the parastichies increase approximately $50^{\circ}$ clockwise between consecutive nodes, while in normal plants the angles increase approximately $87^{\circ}$. The plant architecture is changed. The triple plagiotropic branch is a putative mutant with potential to be explored in coffee breeding programs. The hypotheses for the origin of the mutation and the research perspectives are discussed.
\end{abstract}

Key words: Coffea, mutant, breeding, orthotropic, dimorphism.

\section{INTRODUCTION}

The genus Coffea L. currently comprises 124 species (Davis et al. 2011). Two cultivated species account for almost all the world coffee production and consumption: C. arabica L. (arabica coffee) and C. canephora Pierre ex A. Froehner (robusta coffee). Brazil is the most important coffee producer, exporter and stock holder, and the second largest consumer.

Coffee tree is a shrub characterized by a continuous growth and dimorphic branches. An orthotropic stem grows vertically and forms, at each node, two plagiotropic branches, in opposite phyllotaxy. The plagiotropic branches grow near-horizontally from the orthotropic stem. They originate from axillary buds at leaf bases and are differentiated, two by two in each node, at the leaf insertion point, with angles that approximate $180^{\circ}$.

The orthotropic stem, in primary growth, presents an oval-rectangular cross-section related to the arrangement of the vascular tissue and release of the leaves. The consecutive nodes of an orthotropic stem are organized in parastichies, which are hypothetical spiral lines that connect the pairs of plagiotropic branches to the orthotropic stem, resulting in a cone-shaped tree.
Crop Breeding and Applied Biotechnology 17: 408-411, 2017 Brazilian Society of Plant Breeding. Printed in Brazil http://dx.doi.org/10.1590/1984$70332017 v 17 n 4 n 61$
*Corresponding author: E-mail: sakiyama@ufv.br

Received: 12 October 2017 Accepted: 18 October 2017

\footnotetext{
${ }^{1}$ Universidade Federal de Viçosa (UFV), Departamento de Fitotecnia, 36.570-000, Viçosa, MG, Brazil

${ }^{2}$ UFV, Departamento de Biologia Vegetal ${ }^{3}$ Embrapa Café. Current address: Empresa de Pesquisa Agropecuária de Minas Gerais (EPAMIG), Unidade Regional Zona da Mata, Vila Gianetti, 46, Campus da UFV, 36.570-000, Viçosa, MG, Brazil

${ }^{4}$ Embrapa Café. Current address: UFV, Bioagro

${ }^{5}$ UFV, Departamento de Fitopatologia ${ }^{6}$ EPAMIG
} 
The angles of the parastichies increase approximately $90^{\circ}$ clockwise between consecutive nodes counted from the plant apices. On the other hand, the plagiotropic branches show almost no angulation between consecutive nodes, which results in a flat branch.

It is in the axils of the leaves of the plagiotropic branches that flower buds are formed. Therefore, the number of plagiotropic branches is associated with the production capacity of beans. We report here mutant plants of $C$. arabica with triple plagiotropic branch, resulted from the whorled phyllotaxy of the orthotropic stem.

\section{Description of triple plagiotropic branch}

Six mutant plants of $C$. arabica with three plagiotropic branches per node, resulted from the whorled phyllotaxy of the orthotropic stem, were identified at the Federal University of Viçosa, Brazil, in a population of 700 plants of Catuaí Vermelho. The mutant plants show three plagiotropic branches at each and every node of the main orthotropic stem, differing from a normal plant with two plagiotropic branches per node (Figure 1). Three leaves arise at the apical node of the orthotropic stem, preceding the three plagiotropic branches.

In mutant plants three plagiotropic branches of the same node are separated by angles of approximately $120^{\circ}$ (Figure $1 \mathrm{~A})$, while in normal plants two plagiotropic branches are separated by angles of approximately $180^{\circ}$ (Figure $1 B$ ). The consecutive nodes of the orthotropic stem are organized in parastichies (Figure 1C, 1D and 1E). In mutant plants the angles of the parastichies increase approximately $50^{\circ}$ clockwise between consecutive nodes counted from the
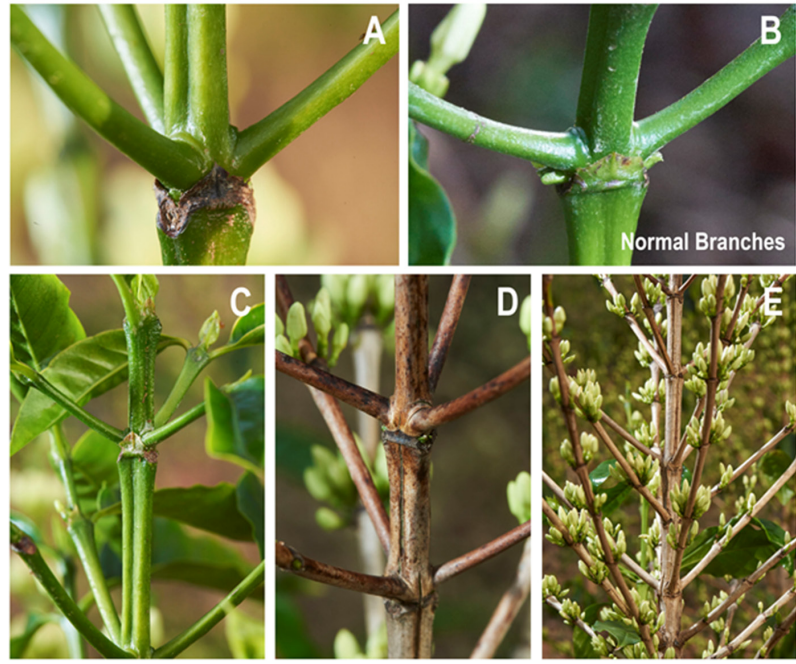

Figure 1. Mutant plant of Coffea arabica with three plagiotropic branches (A, C, D, E) and normal plant with two opposite plagiotropic branches (B). plant apices, while in normal plants the angles increase approximately $87^{\circ}$. The consequences on the plant architecture are obvious.

The whorled phyllotaxy is not present in plagiotropic branches, which maintain the opposite phyllotaxy of a normal plant. The angle between a plagiotropic branch and the orthotropic stem is approximately the same of a normal plant. The number of nodes per plagiotropic branch is also approximately the same of a normal plant, which is observed in the flowering as well. Based on observation of two mutant plants, the secondary orthotropic stem sprouts are normal, with opposite phyllotaxy.

A triple plagiotropic branch mutant plant was also identified in the nursery and was compared with a normal plant. There is a variation in the primary structure of the orthotropic stem. It is triangular in plant with three whorled plagiotropic branches (Figure 2A) and oval-rectangular in normal plant (Figures 2B).

Preliminary anatomic observations of the orthotropic stem (transverse sections below the first developing node, transition from primary to secondary growth) show that the plant with three whorled plagiotropic branches exhibits a triangularly lobed vascular tissue where the cambium is already established, despite the apical position. (Figure $2 \mathrm{C}$ and 2E). The normal plant with two opposite plagiotropic branches exhibits an oval-rectangular vascular tissues, both xylem and phloem, with cambium established (Figures 2D and 2F).

\section{Origin of triple plagiotropic branch}

The origin of the triple plagiotropic branch mutant is probably related to the shoot apical meristem functioning. We briefly argument four hypotheses bellow:

\section{Mutation at the shoot apical meristem}

The vegetative shoot apical meristem of eudicot is partitioned into layers superimposed to a tunica-corpus 
organization (Dickson 2000, Evert 2006, George et al. 2008). The innermost corpus displays various division planes. The layers L1 and L2 cells divide anticlinally. L1 forms the epidermis and L2 forms part of the mesophyll. Three types of chimera may occur in the shoot apical meristem defined by the arrangement of the mutant cells: sectorial, mericlinal, and periclinal. They may not be inherited by the progeny through seeds. However, a mutation (total or on layer L2) may be inherited by the progeny through seeds if the mutant cells contribute to the megasporogenesis and microsporogenesis.

\section{Gene mutation from the gametes or from the zygote onwards that is affecting the shoot apical meristem}

Observing that the evaluated plants exhibited the whorled shoot characteristic from the early stage of development, it is plausible to infer that any modification occurring in the plant shoot apical meristem starts either at the embryo stage or early plantlet stage.

\section{Common ancestor}

Some genera in Rubiaceae display the whorled phyllotaxy (Lantz and Bremer 2005, Wanderley et al. 2007). If we assume that it is a characteristic of a common ancestor, it could be recovered in occasional plant individuals of related species in the event of a mutation.

\section{Hormonal dysfunction, such as in auxin or its receptors at the shoot apical meristem}

Considering that the leaf phyllotaxy is controlled by
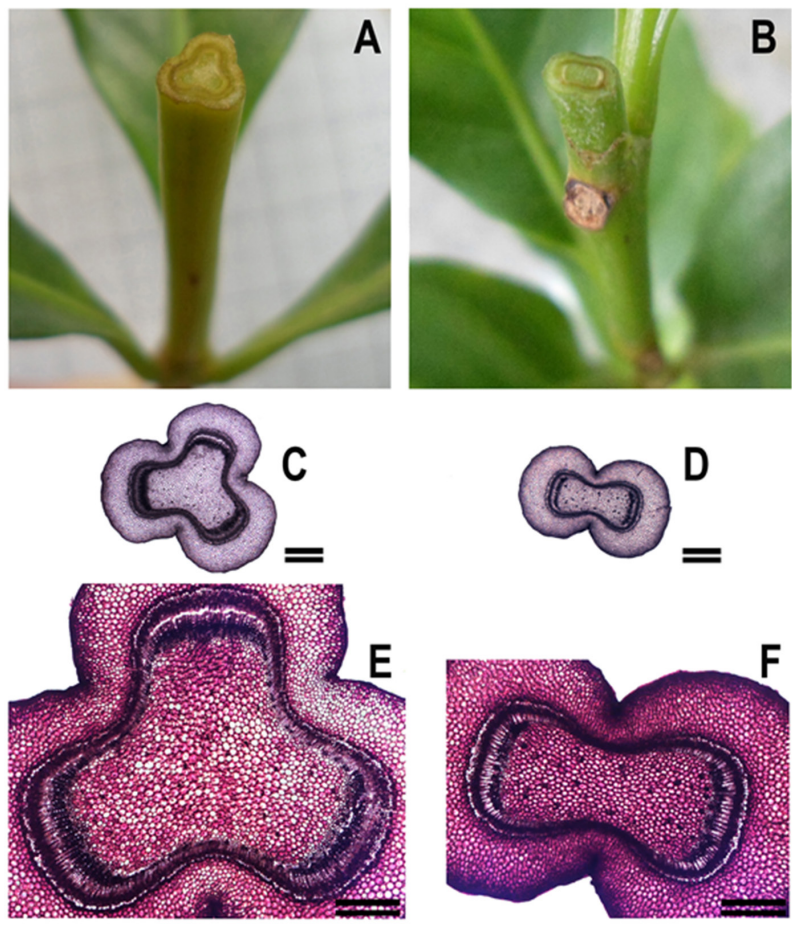

Figure 2. Transverse sections of Coffea arabica orthotropic stem before the development of the plagiotropic branches. Transition from primary to secondary growth of the stem: mutant with three whorled leaves $(A, C, E)$ and a normal plant with two opposite leaves $(B, D, F)$. Detail of the cortex, vascular tissues with the cambium installed and the orthotropic stem pith of the plant with three whorled leaves $(\mathrm{E})$; detail of the cortex, vascular tissues with the cambium installed and the orthotropic stem pith of the plant with two opposite leaves (F). C and D, without stain; $E$ and F, Safranin stained. Bars: $C$ and $D=400 \mu \mathrm{m} ; E$ and $F=200 \mu \mathrm{m}$. the shoot apical meristem, and respond to auxin flux, modifications in the expression of homeotic genes (Carraro et al. 2006, Peaucelle et al. 2007), in auxin or auxin receptors (Carraro et al. 2006, Peaucelle et al. 2007, Trass 2013) or other features (Peaucelle and Laufs 2007, Trass 2013), heritable or not, are entitled to respond for the whorled shoot characteristic. We do not discard the hormonal dysfunction caused by herbicides.

\section{Research perspectives}

The genetic basis of the triple plagiotropic branch mutation in coffee must be studied with focus on its application in breeding programs. The frequency of this mutant in the field and nursery is very low and most of these plants may not inherit the characteristic through seeds, depending on the origin of the mutation. An effort should be made to find a mutant plant whose characteristic is heritable through seeds. If the characteristic is controlled by a single gene or oligogenes, it would be feasible to transfer it to all known cultivars through backcrossing. The molecular approach would be appropriate for studies on genetic basis and marker assisted selection. If the characteristic is due to periclinal or mericlinal mutation of the meristem, the tissue culture approach may be useful for propagation of plants with the whorled stem phenotype.

The cultivation of arabica coffee with triple plagiotropic branch plants should be field tested. The cultivation may be different, considering that each plant would produce $1 / 3$ of additional plagiotropic branches. It is feasible to expect that an improved cultivar with triple plagiotropic branch provides increased production, especially in early years. This 
production increase may change according to the structural adaptations due to the whorled arrangement of the branches. This new arrangement may have a significant effect on light harvesting, photosynthesis and root development, with implications for crop management, such as planting spacing, fertilization, pruning, mechanical harvesting, and others. The secondary orthotropic stem sprout, with normal opposite phyllotaxy, is a characteristic that should not be necessarily disadvantageous, but its consequences on cultivar reproduction and management should be also investigated.

The variation in the external morphology of the primary stem indicates possible changes of stem and leaves vascularization, which may imply in other differential properties of the mutant coffee plant. An anatomical approach of the stem is necessary to investigate possible changes due to the whorled disposition of the plagiotropic branches, along with the evaluation of the anatomy of the leaf and root structures. More detailed analysis of this anatomical configuration must be performed to ascertain if there is an additional adjustment of the vascular tissue when the leaf trace is set, as well as if there is supplementary growth of these vascular tissues in the secondary stem.

\section{CONCLUSIONS}

The triple plagiotropic branch is a coffee putative mutant to be investigated, with the potential to be explored through breeding and crop management.

\section{ACKNOWLEDGEMENT}

The authors are thankful to the Conselho Nacional de Desenvolvimento Científico e Tecnológico (CNPq) for their financial support and to André Berlinck for the photos of Figure 1.

\section{REFERENCES}

Carraro N, Peaucelle A, Laufs P and Traas J (2006) Cell differentiation and organ initiation at the shoot apical meristem. Plant Molecular Biology 60: 811-826.

Davis AP, Tosh J, Ruch N and Fay MF (2011) Growing coffee: Psilanthus (Rubiaceae) subsumed on the basis of molecular and morphological data; implications for the size, morphology, distribution and evolutionary history of Coffea. Botanical Journal of the Linnean Society 167: 357-377.

Dickson WC (2000) Integrative plant anatomy. Academic Press, San Diego, $533 p$.

Evert RF (2006) Esau's Plant Anatomy. $3^{\text {rd }}$ edn, John Wiley \& Sons, New Jersey, 601p.

George EF, Hall MA and De Klerk GJ (2008) Plant Propagation by tissue culture. v. $1,3^{\text {rd }}$ edn, Springer, Dordrecht, 501p.
Lantz H and Bremer B (2005) Phylogeny of the complex Vanguerieae (Rubiaceae) genera Fadogia, Rytigynia, and Vangueria with close relatives and a new circumscription of Vangueria. Plant Systematics and Evolution 253: 159-183.

Peaucelle A and Laufs P (2007) Phyllotaxy, beyond the meristem and auxin comes the miRNA. Plant Signaling \& Behavior 2: 293-295.

Peaucelle A, Morin H, Traas J and Laufs P (2007) Plants expressing a miR164-resistant CUC2 gene reveal the importance of postmeristematic maintenance of phyllotaxy in Arabidopsis. Development 134: 1045-1050.

Traas J (2013) Phyllotaxis. Development 140: 249-253.

Wanderley MGL, Shepherd GJ, Melhem TSA and Giulietti AM (2007) Flora fanerogâmica do estado de São Paulo: Araliaceae Basellaceae Bombacaceae Bromeliaceae Cactaceae Ebenaceae Flacourtiaceae Menispermaceae Phytolaccaceae Podostemaceae Quiinaceae Rubiaceae. v. 5, Instituto de Botânica, São Paulo, 523p. 